\title{
ISCED FIELDS OF EDUCATION AND TRAINING 2013 (ISCED-F 2013)
}

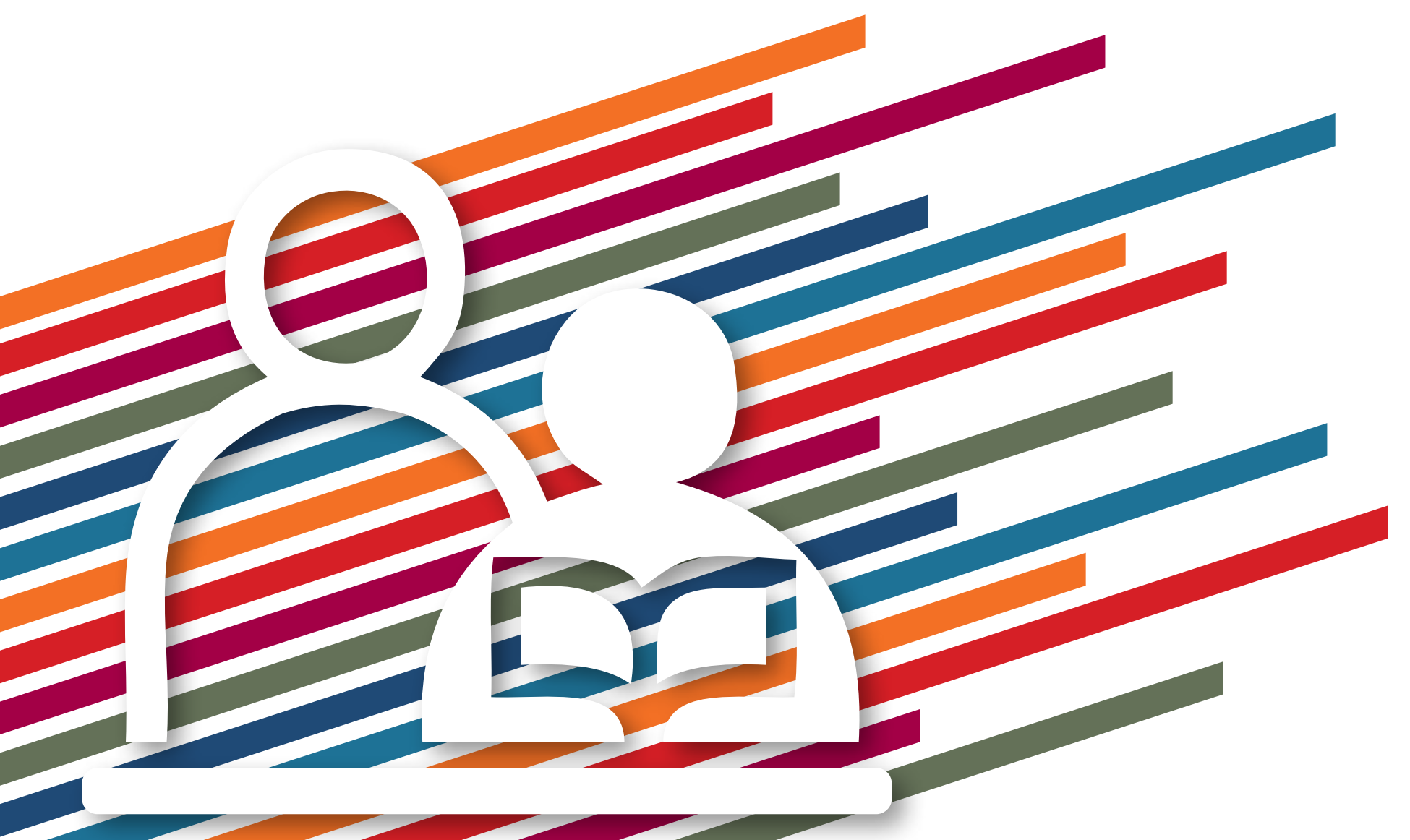

Manual to accompany the International Standard Classification of Education 2011 


\section{UNESCO}

The constitution of the United Nations Educational, Scientific and Cultural Organization (UNESCO) was adopted by 20 countries at the London Conference in November 1945 and entered into effect on 4 November 1946. The Organization currently has 195 Member States and 9 Associate Members.

The main objective of UNESCO is to contribute to peace and security in the world by promoting collaboration among nations through education, science, culture and communication in order to foster universal respect for justice, the rule of law, and the human rights and fundamental freedoms that are affirmed for the peoples of the world, without distinction of race, sex, language or religion, by the Charter of the United Nations.

To fulfil its mandate, UNESCO performs five principal functions: 1) prospective studies on education, science, culture and communication for tomorrow's world; 2) the advancement, transfer and sharing of knowledge through research, training and teaching activities; 3 ) standard-setting actions for the preparation and adoption of internal instruments and statutory recommendations; 4) expertise through technical co-operation to Member States for their development policies and projects; and 5) the exchange of specialized information.

UNESCO is headquartered in Paris, France.

\section{UNESCO Institute for Statistics}

The UNESCO Institute for Statistics (UIS) is the statistical office of UNESCO and is the UN depository for global statistics in the fields of education, science and technology, culture and communication.

The UIS was established in 1999. It was created to improve UNESCO's statistical programme and to develop and deliver the timely, accurate and policy-relevant statistics needed in today's increasingly complex and rapidly changing social, political and economic environments.

The UIS is based in Montreal, Canada.

Published in 2014 by:

UNESCO Institute for Statistics

P.O. Box 6128, Succursale Centre-Ville

Montreal, Quebec H3C 3J7

Canada

Tel: $\quad+1-514-343-6880$

Email: uis.publications@unesco.org

http://www.uis.unesco.org

CUNESCO-UIS 2014

ISBN 978-92-9189-150-4

Ref: UIS/2014/INS/4 REV

DOI http://dx.doi.org/10.15220/978-92-9189-150-4-en

This publication is available in Open Access under the Attribution-ShareAlike 3.0 IGO (CC-BY-SA 3.0 IGO) license (http://creativecommons.org/licenses/by-sa/3.0/igo/). By using the content of this publication, the users accept to be bound by the terms of use of the UNESCO Open Access Repository (http://www.unesco.org/open-access/terms-use-ccbysa-en).

The designations employed and the presentation of material throughout this publication do not imply the expression of any opinion whatsoever on the part of UNESCO concerning the legal status of any country, territory, city or area or of its authorities or concerning the delimitation of its frontiers or boundaries. 


\section{Contents}

Page

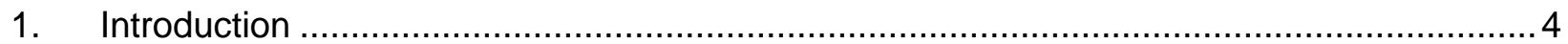

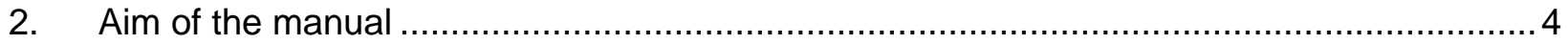

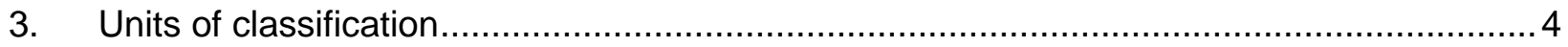

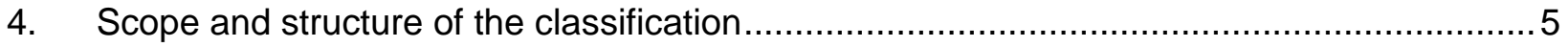

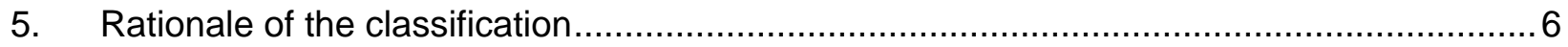

6. Application of classification criteria: Some examples .............................................. 7

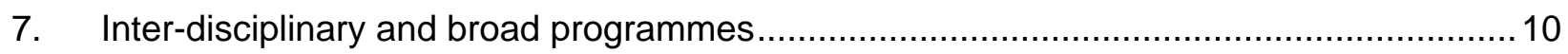

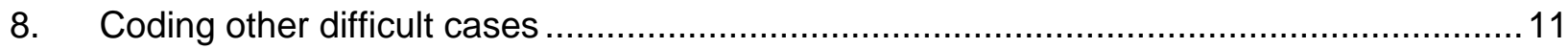

9. Aggregations for analysis and publication ...................................................... 12

10. Relation to ISCED 2011 and other classifications ................................................ 13

Appendix I. ISCED fields of education and training ................................................... 18 


\section{Introduction}

1. The International Standard Classification of Education (ISCED) is a framework for assembling, compiling and analysing cross-nationally comparable statistics on education. ISCED is a member of the United Nations International Family of Economic and Social Classifications and is the reference classification for organizing education programmes and related qualifications by levels and fields of education. First developed in the mid-1970s by the United Nations Educational, Scientific and Cultural Organization (UNESCO), ISCED has been revised twice - most recently in 2011. ISCED is a product of international agreement and was adopted formally by the General Conference of UNESCO Member States.

2. The latest revision, ISCED 2011, concentrated primarily on changes to the levels of education of programmes (ISCED-P) and introduced, for the first time, a classification of levels of educational attainment based on qualifications (ISCED-A).

3. During the review process which led to the 2011 revision, it was decided that the fields of education should be examined in a separate process to establish an independent but related classification which could be updated according to a different frequency, if appropriate, from any future revision to the levels of education and educational attainment. The classifications of levels and fields will remain part of the same family of classifications. Accordingly, this new classification will be referred to as the ISCED Fields of Education and Training (ISCED-F).

\section{Aim of this manual}

4. The availability of a common international classification is only the first step towards the collection of comparable data. The second step is to ensure a consistent application of the classification across countries. Thus, the aim of this manual is to offer clear guidelines on how to apply the ISCED Fields of Education and Training. This is done by both specifying a number of criteria to be observed and by providing lists of inclusions and exclusions from each field of education and training. The detailed ISCED Fields of Education and Training classification is described in Appendix I. The classification will be accompanied by a comprehensive listing of the definitions of each field and examples of subjects that are included and excluded within each field in order to assist countries in defining the boundaries between each field. The comprehensive listing will include both an alphabetical and a numerical list for ease of reference.

\section{Units of classification}

5. The basic units of classification in ISCED 2011 are education programmes and their related qualifications. These are the same units of classification in the ISCED Fields of Education and Training (ISCED-F):

a. An education programme is "a coherent set or sequence of educational activities designed and organized to achieve pre-determined learning objectives or accomplish a specific set of educational tasks over a sustained period of time". Educational activities are "deliberate activities involving some form of communication intended to bring about learning". 
b. A qualification is the "official confirmation, usually in the form of a document certifying the successful completion of an education programme. Credits awarded for the successful completion of individual courses (e.g. modules or subjects) are not considered as qualifications within ISCED. In such cases, a sufficient number of credits or subjects equivalent in duration and/or covering the curriculum of a full programme would represent a qualification".

6. ISCED Fields of Education and Training classifies education programmes and related qualifications by fields of study:

a. A field is the "broad domain, branch or area of content covered by an education programme or qualification".

7. Fields of education and training and levels of education or educational attainment are cross-classification variables within ISCED and are therefore independent of each other. In particular, unlike the original ISCED 1976, fields are not defined within levels of education. This is because at some levels of education, while programmes and qualifications are only available in some fields of education and training, this can vary between countries or over time. For example, teacher training or nursing are offered at different levels of education in different countries. Over recent years there has been a tendency for such programmes to be phased out at lower levels of education and the training to be up-graded to a higher ISCED level.

\section{Scope and structure of the classification}

8. This classification has been designed principally to describe and categorise fields of education and training at the secondary, post-secondary and tertiary levels of formal education as defined in ISCED 2011, though it may be used for classifying programmes and qualifications offered at other levels. The classification may also be used in other contexts, for example to classify the subject matter of non-formal education, initial and continuing vocational training, or informal learning.

9. The current revision builds on earlier versions of the classification in order to ensure as far as possible that there is comparability over time. It has been designed as a three-level hierarchy between broad fields (the highest level), narrow fields (the second level) and detailed fields (the third level), and uses a four-digit coding scheme. There are 11 broad fields, 29 narrow fields and about 80 detailed fields of education and training.

\begin{tabular}{llc} 
Level & Categories of fields & Number of fields \\
\hline $1^{\text {st }}$ level & Broad field & 11 \\
$2^{\text {nd }}$ level & Narrow field & 29 \\
$3^{\text {rd }}$ level & Detailed field & $\cong 80$
\end{tabular}


10. The detailed fields (the third hierarchical level of the classification) are intended mainly for use at the tertiary level of education and, for vocational education and training programmes and qualifications at secondary and post-secondary non-tertiary levels. The classification can also be used for programmes and qualifications of general education where there is a subject specialisation. However, general education programmes and qualifications which cover a broad range of subjects with little or no specialisation in a particular field or fields will typically be classified within the broad field 00 'Generic programmes and qualifications'.

11. Whilst the classification has been developed mainly for the purpose of compiling crossnationally comparable statistics on education, it can also be used in national contexts, especially in countries which have not yet developed their own standard national classifications of fields of education. It is likely that countries wishing to adopt this classification for national use will need to adapt or adjust certain groupings of fields to better reflect the incidence and/or range of fields available to study in the country and to meet national needs for reporting education data of this type. National adjustments should not make international reporting according to ISCED Fields of Education and Training difficult or impossible. The primary aim of the ISCED classification is to facilitate international reporting at least at the broad fields' level.

\section{Rationale of the classification}

12. The classification of fields of education and training follows a subject matter approach. This is the same approach as used in previous versions of ISCED (1976, 1997 and 2011). Where content is closely related, subjects are grouped together to form the broad, narrow and detailed fields of classification, based on the similarity of the subject matter. The aim is to classify education programmes and their related qualifications by fields of education and training on the basis of the content of the programme and not the characteristics of the intended participants.

13. It is the main subject matter which determines the field of education and training into which a programme or qualification should be classified. Subject matter is the factual, practical and theoretical knowledge imparted during the programme and which is recognised by the related qualification. This knowledge is applied to particular types of problems or for specific purposes which may be abstract (e.g. philosophy), practical (e.g. engineering) or both (e.g. architecture). For practical purposes, the main subject of a programme or qualification is determined by the detailed field in which the majority (i.e. more than $50 \%$ ) or clearly predominant part of learning credits or of students' intended learning time is spent. Learning credits, where available, should be used. Otherwise, an approximate assessment of the intended learning time should be made. Learning time includes that spent in lectures and seminars, as well as in laboratories or on special projects. Private study time is excluded (as it is difficult to measure and varies between students). Programmes and qualifications are classified in the detailed field containing their main subject.

14. Where there is insufficient information available to determine the relative shares of learning credits or intended learning time, the programme or qualification should be classified in the field listed first in its title. Where a main subject cannot be identified because the programme or qualification covers several detailed fields (and, even, narrow or broad fields) none of which dominates, the programme or qualification should be classified in an interdisciplinary category. (See Section 7 for further details.) 
15. Two programmes or qualifications belong to the same field if the main subjects studied are the same or are sufficiently similar. In developing the structure of the classification, the following criteria were used in priority order when determining the degree of similarity of the subject matter in order to classify the fields of education and training into broad, narrow and detailed fields:

a. Theoretical knowledge content (i.e. the ideas and concepts involved and their use in explaining facts and predicting outcomes).

b. Purpose of learning (i.e. the intended use of the knowledge, skills and competencies gained).

c. Objects of interest (i.e. the phenomena, problems or entities being studied).

d. Methods and techniques (i.e. procedures for learning and applying the skills and knowledge gained).

e. Tools and equipment (i.e. the instruments and implements which an individual learns to use or operate).

16. Ideally, the classification would be broadly 'balanced' across broad fields at the international level, meaning that across the world as a whole no single broad field should dominate. For example, when counting the number of enrolments in or graduates from education programmes, disproportionate numbers of enrolments/graduates concentrated in one broad field rather than another should not be expected. However, given the wide variations in education systems between countries and also between levels of education, it is not possible to develop a single classification which is balanced for all countries or all levels of education.

\section{Application of classification criteria: Some examples}

17. The broad and narrow field categories in this classification are similar to those in ISCED 1997. They are largely determined by similarities in theoretical knowledge and the purpose of learning, and to a lesser extent, the objects of interest of the group of fields they cover. The detailed fields are largely distinguished on the basis of methods and techniques and tools and instruments. The rest of this section describes some examples of the application of these criteria, borderline cases and two specific exceptions: vocational programmes and qualifications and teacher training.

\section{Subject matter similarity across levels of education}

18. All education programmes and qualifications are associated with a blend of theoretical understanding, factual knowledge and practical skills. Two programmes or qualifications at different levels of education will belong to the same field of education and training if they cover similar types of theoretical, factual and practical knowledge or skills, even if the relative emphasis given to each may be different. For example, a tool-making programme includes some of the mathematics, factual knowledge and engineering theory used in mechanical engineering. Thus, tool-making and mechanical engineering should have the same field of education and training (0715 'Mechanics and metal trades'), despite being associated with different levels of education or educational attainment. 


\section{Subject matter similarity within levels of education}

19. By contrast, 'Nursing and midwifery' is classified as 0913 and 'Medicine' as 0912 . Whilst they are closely related, there are differences in subject matter - especially the purpose of learning (doctors and nurses are expected to acquire and apply different knowledge, skills and competencies), methods and techniques, and even tools and equipment. There is also a strong interest amongst data users to be able to differentiate between nurses and doctors. In some countries, doctors and nurses study and qualify at the same levels of education. In these cases, differentiation between them is more easily made through fields than levels of education.

\section{Borderline cases}

20. Borderline cases occur where a programme or qualification is closely related to two different fields in the classification. For example, veterinary studies has similarities both with medicine (theoretical knowledge especially but also purpose of learning) and animal husbandry (the objects of interest, methods and techniques, and tools and equipment). The latter has been chosen for classifying veterinary studies in order to maintain correspondence between previous versions of ISCED, with key related classifications (e.g. the Fields of Science and the International Standard Industrial Classification of All Economic Activities (ISIC)) and to preserve a broad field devoted to (Human) Health and Welfare which is important for national policy analysis.

21. Another example is care. Medical care has been classified in narrow field 091 'Health' and non-medical care in narrow field 092 'Welfare' on the grounds that the theoretical knowledge required for the two fields is very different.

\section{Generic programmes}

22. Generic programmes which cover a range of subjects, such as languages and literature, social and natural sciences, mathematics, arts and/or physical education, should be classified in 0011 'Basic programmes and qualifications'. This should be the case even if there is some concentration on a certain category of subject matter, such as humanities, social sciences, natural sciences, etc., which can occur. These programmes are a specific type of inter-disciplinary or broad programme for which a broad field has been created. They should therefore not be classified in other broad fields as inter-disciplinary or broad programmes.

\section{Programmes and qualifications for engineers}

23. Education programmes and qualifications for engineers should be included in the detailed fields under 071 'Engineering ${ }^{1}$ and engineering trades' or, for civil or construction engineers, in 0732 'Building and civil engineering'. Even if the studies are oriented towards computing, media techniques, textiles, food, etc., they should be classified under 071 or 0732 if the emphasis is on designing and constructing machinery, engines, electrical devices, electronics, computers, telecommunications, etc. (071) or buildings, roads and bridges (0732).

1 Note that 'Engineering' is a much broader concept encompassing other categories than just an engineer, who works as a professional in Engineering. There is no difference intended between detailed fields 071 and 072 in terms of level of education. 


\section{Manufacturing programmes}

24. Manufacturing programmes should be classified in the detailed fields under 071 'Engineering and engineering trades' if the emphasis is towards engineering, i.e. on metals, mechanics, machinery, engines, electrical devices, etc.

25. Other manufacturing programmes and qualifications should be classified under 072 'Manufacturing and processing'. This is the case where the emphasis is on manufacturing specific products, such as food, textiles, shoes, paper, furniture, glass, plastic, etc., However, manufacturing of metal products is excluded from narrow field 072 and included in detailed field 0715 'Mechanics and metal trades'.

\section{Languages}

26. Languages should be classified as either detailed field 0231 'Language acquisition' or detailed field 0232 'Literature and linguistics' based on the characteristics of the intended participants $^{2}$ (as, in this particular case, this is a proxy for the subject matter of the studies). There is a clear difference between the theoretical content, purpose of learning and teaching style of programmes and qualifications designed for existing native or fluent speakers of a language and those designed for speakers of other languages who are trying to acquire a given language. In the former case, the emphasis will be on the literature and linguistics of the language rather than the grammar and vocabulary (at least at secondary and tertiary levels of education). In the latter case, the focus will be on grammar and vocabulary and perhaps culture and rather less on literature and linguistics.

\section{Vocational programmes and qualifications including subsidiary subjects}

27. In vocational programmes, for example some long programmes in upper secondary education, more time in total may be devoted to subsidiary subjects than the main subject matter of the intended occupation or class of occupations. Nevertheless, such programmes and their resulting qualifications should be classified in the vocational field associated with the intended occupation or class of occupations. This is an exception to the rule on the classification according to the majority or predominant subject as it is important to be able to identify separately target occupation(s) of vocational programmes and qualifications. In practice, it is likely that the field of the target occupation(s) is the one to which the greatest intended learning time is devoted.

Example 1: A nursing health care programme should be classified in detailed field 0913 'Nursing and midwifery', even if more intended learning time in total is devoted to other subjects than nursing.

\section{Teacher training programmes and qualifications with a subject matter specialisation}

28. Teacher training programmes and qualifications focused primarily on teaching a subject matter specialisation should be classified as teacher training even if the main content is a subject matter specialisation. The same principle should be applied to programmes and qualifications which combine education or teacher training and a specialised subject. This is an exception to the majority or predominant subject rule on the classification of programmes and qualifications as it is important to be able to identify separately teacher training from other detailed fields, especially in analyses of education systems.

2 i.e. whether learners are already proficient in the language to be studied or not. 


\section{Inter-disciplinary or broad programmes and qualifications}

29. Inter-disciplinary or broad programmes and qualifications are those which combine several detailed fields of education and training where no single detailed field dominates. Many inter-disciplinary programmes and qualifications cover several narrow or even broad fields. In this classification, the 'leading subject rule' is used to determine the broad field into which the inter-disciplinary study should be classified. That is, the leading subject or subjects determines the (broad) field. The criterion for determining the leading subject(s) is, as before, the share of learning credits or students' intended learning time. Inter-disciplinary programmes should be classified by using ' 8 ' at the narrow and detailed field levels (i.e. xx88) within the leading broad field as 'Inter-disciplinary programmes or qualifications involving [the broad field]'. Thus all inter-disciplinary study with no dominant subject will be separately identified and, at least, the leading broad field of the programme or qualification will be known.

Example 2: A programme consisting of equal parts (one-third each) of theology (0221), history (0222) and philosophy (0223) should be classified as 0288 ('Inter-disciplinary programmes and qualifications involving arts and humanities'). If a programme consists of $60 \%$ theology, 20\% history and 20\% philosophy, it should be classified as 0221 as theology is the dominant subject.

30. Where more than one leading broad field is identified, the inter-disciplinary study should be classified in the broad field listed first in the title (or in the curriculum or syllabus if not listed in the title) of the programme or qualification. Where there is insufficient information to determine the leading subject, the 'first-listed' rule described in the previous sentence should be applied.

31. Programmes or qualifications covering two or more detailed fields where one detailed field represents the predominant share of the learning credits or intended learning time should be classified in that detailed field. Thus, if the major share of learning credits or intended learning time is devoted to a single detailed field, the programme/qualification should be classified in that detailed field and not as an inter-disciplinary programme/qualification.

Example 3: A programme majoring in mathematics with a minor in French should be classified as 0541 'Mathematics' as it is the dominant subject.

Example 4: A programme consisting of 40\% engineering (071), 30\% business (041) and $30 \%$ languages (023) should be classified as 0788 ('Inter-disciplinary programmes and qualifications involving engineering, manufacturing and construction') as no field predominates but 07 is the leading broad field. If engineering and business were equally important and greater than languages (e.g. 40\%, 40\% and 20\%), the programme would be classified as either 0788 or 0488 depending on which programme, engineering (071) or business (041), is listed first in the programme title (or, if not in the title, in the curriculum or syllabus).

Example 5: A programme consisting of 40\% history (0222), 30\% economics (0311) and $30 \%$ politics (0312) would be classified as 0388 ('Inter-disciplinary programmes and qualifications involving social sciences, journalism and information') as economics and politics are in the same broad field. 
32. Programmes and qualifications aimed at one specific vocational field consisting also of subsidiary subjects from other fields are not considered as inter-disciplinary programmes or qualifications and should be classified according to the specific vocational field.

Example 6: In a programme in electrical installation, more time may be devoted to subsidiary subjects (language, mathematics, natural sciences, etc.) than the intended vocational subject. However, this programme should be classified as 0713 'Electricity and energy' and not as an inter-disciplinary programme.

33. The 'leading subject rule' is the only feasible solution for classifying inter-disciplinary programmes and qualifications as long as only one code can be assigned as is recommended in this manual. However, users who are able to assign two or more codes ${ }^{3}$ may be able to classify inter-disciplinary programmes or qualifications to combinations of fields.

\section{Coding other difficult cases}

\section{Not further defined and not elsewhere classified}

34. Two common situations need to be addressed within the classification of fields of education and training when coding programmes or qualifications in specific data collections:

a. Cases where there is no further information about a given programme or qualification than that known at a higher level of the classification. These are known as cases which are 'not further defined' and are designated by the use of one or more ' 0 ' at the end of codes at the narrow or detailed fields hierarchical levels of the classification (as appropriate).

Example 7: A programme in engineering where more information is not available should be classified as 0710 'Engineering and engineering trades not further defined'. Such cases should not be considered as inter-disciplinary or broad programmes.

Example 8: A programme in services where more information is not available should be classified as 1000 'Services not further defined'.

b. Cases where the particular detailed field is known and adequately described but is not explicitly provided for in the classification. These are known as cases which are 'not elsewhere classified' and are designated by the use of ' 9 ' at the detailed field level of the classification (i.e. as the last digit).

Example 9: A programme in a new field in ICTs which does not belong to any of the other detailed fields should be classified as 0619 'Information and Communication Technologies not elsewhere classified'.

3 For example, where data are stored in registers and do not need to be collected by means of household or other surveys. Using multiple codes is not part of ISCED-F. However, some countries may decide to use multiple codes for national purposes. 
These 'not further defined' and 'not elsewhere classified' codes are not included in the classification structure but are supplementary codes which can be used when processing data which are not adequately or sufficiently described ('not further defined') or which are not explicitly covered in the classification structure ('not elsewhere classified').

It can be difficult to differentiate the use of "0", " 8 " and "9". Table 1 may be of assistance.

Table 1. Supplementary codes

\begin{tabular}{|c|c|c|c|}
\hline Code & Name & Use & Example \\
\hline 0 & Not further defined & $\begin{array}{l}\text { No further information than is } \\
\text { known at a higher level of the } \\
\text { classification }\end{array}$ & 7 and 8 \\
\hline 8 & $\begin{array}{l}\text { Inter-disciplinary } \\
\text { programmes or } \\
\text { qualifications }\end{array}$ & $\begin{array}{l}\text { Programmes or qualifications } \\
\text { with no dominant detailed } \\
\text { field }\end{array}$ & $\begin{array}{l}2 \text { (first part), } 4 \\
\text { and } 5\end{array}$ \\
\hline 9 & Not elsewhere classified & $\begin{array}{l}\text { The detailed field is known } \\
\text { but not provided for in the } \\
\text { classification }\end{array}$ & 9 \\
\hline
\end{tabular}

Note: Programmes and qualifications with a dominant detailed field (comprising more than $50 \%$ of learning credits or time) are classified in that dominant field (see Examples 1, 2 (second part), 3 and 6).

35. During data collection, where the field of study is completely unknown, a code of ' 9999 ' can be assigned or, in surveys which are limited to the narrow or broad field levels only, '999' or '99' respectively.

\section{Aggregations for analysis and publication}

36. This classification can be used at any of the hierarchical levels for both data collection and dissemination depending on the information needs. It is intended to be sufficiently flexible to serve most purposes of analysis and presentation.

37. There is often a need for a broad aggregation for publication purposes. For example, the UNESCO Institute for Statistics (UIS) publishes data at the broad field level.

38. Due consideration should be paid to the purpose of the analysis. Other groupings than the one currently used by the UIS can be developed, in particular, for dissemination purposes. 


\section{Relation to ISCED 2011 and other classifications}

\section{Relation to ISCED 2011}

\section{Orientation and fields}

39. Orientation (general or vocational education) and fields of education and training are two different dimensions in ISCED and must not be confused.

40. Vocational education is defined in ISCED 2011 as:

Programmes that are designed for learners to acquire the knowledge, skills and competencies specific to a particular occupation, trade or class of occupations or trades. Vocational education may have work-based components. Successful completion of such programmes leads to labour market-relevant vocational qualifications acknowledged as occupationally-oriented by the relevant national authorities and/or the labour market.

41. General education is defined in ISCED 2011 as:

Programmes that are designed to develop learners' general knowledge, skills and competencies, as well as literacy and numeracy skills, often to prepare students for more advanced education programmes at the same or higher ISCED levels and to lay the foundation for lifelong learning.

42. Programmes and qualifications which are classified as general education under orientation according to ISCED 2011 and cover a broad range of subjects without specialisation in a particular field of study should be classified in the 'Generic programmes and qualifications' broad field as 0011 'Basic programmes and qualifications'. Other programmes and qualifications of general education should be classified by field of education and training according to their main subject matter. In particular, general or academic education at the tertiary level should only, by way of exception, be classified in the 'Generic programmes and qualifications' broad field.

Example 10: An education programme or qualification in mathematics at ISCED 2011 level 5 may be general education for orientation, but the detailed field should be 0541 'Mathematics'.

Correspondence between ISCED-F and ISCED 1997 (and 2011) Fields of Education

43. There has been some reassignment of narrow or detailed fields between broad fields in the ISCED Fields of Education and Training 2013 (ISCED-F) in line with the principles of classification described in Section 5 and, in particular, in paragraph 15. These are shown in the following correspondence table (see Table 2).

44. The main changes are:

a. The splitting of Field 22 'Humanities' in ISCED 1997 into two narrow fields: 022 'Humanities (except languages)' and 023 'Languages'.

b. The splitting of Broad Group 3 'Social sciences, business and law' in ISCED 1997 into two broad fields: 03 'Social sciences, journalism and information' and 04 'Business, administration and law'. 
c. The creation of a new narrow field 052 'Environment' within the broad field 05 'Natural sciences, mathematics and statistics' by splitting Field 42 'Life sciences' in ISCED 1997 and combining with some of Field 62 'Agriculture, forestry and fishery'.

d. The splitting of Broad Group 4 'Science' in ISCED 1997 into two broad fields: 05 'Natural sciences, mathematics and statistics' and 06 'Information and Communication Technologies (ICTs)'.

e. The creation of a new narrow field 0712 'Environmental protection technology' by transferring most of Field 85 'Environmental protection' from the Broad Group 8 'Services' to the new broad field 07 'Engineering, manufacturing and construction'.

f. The renaming of Broad Group 6 'Agriculture' in ISCED 1997 to create a new broad field 08 'Agriculture, forestry, fisheries and veterinary' and the transfer of some of Field 62 'Agriculture, forestry and fishery' to the new narrow field 052 'Environment'.

g. The creation of a new narrow field 102 'Safety services' from the remains of Field 85 'Environmental protection' in ISCED 1997. 
Table 2. Correspondence between ISCED Fields of Education and Training 2013 (ISCED-F) and ISCED 1997 Fields of Education

\begin{tabular}{|c|c|}
\hline ISCED Fields of Education and Training 2013 & ISCED 1997 (and 2011) Fields of Education \\
\hline 00 Generic programmes and qualifications & 0 General programmes \\
\hline 001 Basic programmes and qualifications & 01 Basic programmes \\
\hline 002 Literacy and numeracy & 08 Literacy and numeracy \\
\hline 003 Personal skills and development & 09 Personal development \\
\hline 01 Education & 1 Education \\
\hline 011 Education & 14 Teacher training and education science \\
\hline 02 Arts and humanities & 2 Humanities and Arts \\
\hline 021 Arts & 21 Arts \\
\hline 022 Humanities (except languages) & \multirow[t]{2}{*}{22 Humanities } \\
\hline 023 Languages & \\
\hline 03 Social sciences, journalism and information & 3 Social sciences, business and law (minus business and law) \\
\hline 031 Social and behavioural sciences & 31Social and behavioural science \\
\hline 032 Journalism and information & 32 Journalism and information \\
\hline 04 Business, administration and law & 3 Social sciences, business and law (minus social sciences) \\
\hline 041 Business and administration & 34 Business and administration \\
\hline 042 Law & 38 Law \\
\hline 05 Natural sciences, mathematics and statistics & $\begin{array}{l}4 \text { Science (minus computing) } \\
\text { plus natural parks and wildlife from } 62 \text { Agriculture, forestry and } \\
\text { fishery }\end{array}$ \\
\hline 051 Biological and related sciences & 42 Life sciences minus other allied sciences \\
\hline 052 Environment & $\begin{array}{l}\text { Part of } 42 \text { Life sciences (other allied sciences), part of } 62 \\
\text { Agriculture, forestry and fishery (natural parks, wildlife) }\end{array}$ \\
\hline 053 Physical sciences & 44 Physical science \\
\hline 054 Mathematics and statistics & 46 Mathematics and statistics \\
\hline 06 Information and Communication Technologies & 4 Science (Computing only) \\
\hline 061 Information and Communication Technologies & 48 Computing \\
\hline 07 Engineering, manufacturing and construction & $\begin{array}{l}5 \text { Engineering, manufacturing and construction (plus most of } 85 \\
\text { Environmental protection) }\end{array}$ \\
\hline 071 Engineering and engineering trades & $\begin{array}{l}52 \text { Engineering and engineering trades (plus most of } 85 \\
\text { Environmental protection) }\end{array}$ \\
\hline 072 Manufacturing and processing & 54 Manufacturing and processing \\
\hline 073 Architecture and construction & 58 Architecture and building \\
\hline 08 Agriculture, forestry, fisheries and veterinary & 6 Agriculture (minus natural parks and wildlife) \\
\hline 081 Agriculture & \multirow{3}{*}{$\begin{array}{l}62 \text { Agriculture, forestry and fishery (minus natural parks and } \\
\text { wildlife) }\end{array}$} \\
\hline 082 Forestry & \\
\hline 083 Fisheries & \\
\hline 084 Veterinary & 64 Veterinary \\
\hline 09 Health and welfare & 7 Health and welfare \\
\hline 091 Health & 72 Health \\
\hline 092 Welfare & 76 Social services \\
\hline 10 Services & 8 Services (minus most of 85 Environmental protection) \\
\hline 101 Personal services & 81 Personal services \\
\hline 102 Hygiene and occupational health services & $\begin{array}{l}\text { Part of } 85 \text { Environmental protection (community sanitation and } \\
\text { labour protection and security) }\end{array}$ \\
\hline 103 Security services & 86 Security services \\
\hline 104 Transport services & 84 Transport services \\
\hline
\end{tabular}




\section{Relation to the European Union's Fields of Training (FoT 1997) and Fields of Education and Training (FoET 1999)}

45. The European Union's Fields of Training 1997 (FoT 1997) and Fields of Education and Training 1999 (FoET 1999) classifications were developed from the ISCED 1997 classification of fields of education and are consistent with it, apart from minor changes in wording, at the first and second levels (and digits) of the hierarchy. FoET 1999 was developed from FoT 1997 and superceded it. FoET 1999 is a three-level (and 3-digit) hierarchical classification and was the initial starting point for the current revision of ISCED-F.

46. FoET 1999 is used internationally in different data collections, for example:

- Administrative data on enrolment and graduates;

- Certain household surveys; and

- $\quad$ Student assessment surveys.

47. The 1993 Australian Bureau of Statistics Classification of Qualifications (ABSCQ 1993) was used extensively in the development of both FoT 1997 and FoET 1999. Although ABSCQ was superseded in 2001 by the Australian Standard Classification of Education (ASCED), some concepts and text from ABSCQ 1993 are used in the ISCED-F classification as FoET 1999 was a starting point for the revision of the ISCED fields.

\section{Relation to the International Standard Classification of Occupations (ISCO-08)}

48. The International Standard Classification of Occupations (ISCO-08) is a system for classifying and aggregating occupational information obtained from population censuses and other statistical surveys, as well as administrative records. Its main purpose is to provide a basis for the international reporting and comparison of information about jobs and occupations.

a. A job is defined as 'a set of tasks and duties performed or meant to be performed by one person, including for an employer or in self-employment'.

b. An occupation is 'a set of jobs whose main tasks and duties are characterised by a high degree of similarity'. A person may be associated with an occupation through their relationship to a past, present or future job.

49. ISCO-08 uses two basic criteria to arrange occupations into groups: skill level and skill specialisation.

a. Skill is defined as 'the ability to carry out the tasks and duties of a given job'.

b. Skill level is a 'function of the complexity and range of the tasks and duties to be performed'.

c. Skill specialisation is considered in terms of the 'field of knowledge required, the tools and machinery used, the materials worked on or with and the kinds of goods and services produced'. 
50. The concept of skill specialisation within ISCO-08 has some similarity with the fields of education and training within ISCED. However, ISCO-08 and ISCED classify different statistical units using different criteria. ISCED Fields of Education and Training classifies education programmes and qualifications based on their subject matter, whilst ISCO-08 classifies jobs based on the skill level and specialisation required to perform them. There is therefore not always a direct correspondence between the occupational and field groups of the two classifications though links clearly exist.

\section{Relation to the Fields of Science and Technology (FoS 2007) classification}

51. Fields of Science and Technology 2007 (FoS 2007) classifies research and experimental development (R\&D) and is part of OECD's Frascati Manual. The FoS was last revised in 2007 and is available as an electronic annex [http://www.oecd.org/dataoecd/36/44/38235147.pdf]. FoS is a two-level hierarchical classification with six major fields:

1. Natural sciences

2. Engineering and technology

3. Medical and health sciences

4. Agricultural sciences

5. Social sciences

6. Humanities.

These six major fields are divided into approximately 40 second-level fields.

52. The 2007 revision of FoS was needed mainly due to emerging new fields, like information and communications technology, biotechnology and nanotechnology, as well as the emergence of inter-disciplinary sciences.

53. Both ISCO-08 and FoS 2007 have been used to identify new emerging fields for inclusion in ISCED-F.

54. The relevant parts of ISCED-F have also been compared with FoS in order to avoid unnecessary differences. However, it is recognised the FoS and ISCED-F have different purposes and it is not feasible to ensure a direct correspondence between the two classifications. 


\section{Appendix I. ISCED fields of education and training}

\begin{tabular}{|c|c|c|}
\hline Broad field & Narrow field & Detailed field \\
\hline $\begin{array}{l}00 \text { Generic programmes } \\
\text { and qualifications }\end{array}$ & $\begin{array}{l}001 \text { Basic programmes and } \\
\text { qualifications } \\
002 \text { Literacy and numeracy } \\
003 \text { Personal skills and development }\end{array}$ & $\begin{array}{l}0011 \text { Basic programmes and } \\
\text { qualifications } \\
0021 \text { Literacy and numeracy } \\
0031 \text { Personal skills and development }\end{array}$ \\
\hline 01 Education & 011 Education & $\begin{array}{l}0111 \text { Education science } \\
0112 \text { Training for pre-school teachers } \\
0113 \text { Teacher training without subject } \\
\text { specialisation } \\
\text { 0114 Teacher training with subject } \\
\text { specialisation }\end{array}$ \\
\hline \multirow[t]{3}{*}{02 Arts and humanities } & 021 Arts & $\begin{array}{l}\text { 0211 Audio-visual techniques and } \\
\text { media production } \\
0212 \text { Fashion, interior and industrial } \\
\text { design } \\
0213 \text { Fine arts } \\
0214 \text { Handicrafts } \\
0215 \text { Music and performing arts }\end{array}$ \\
\hline & 022 Humanities (except languages) & $\begin{array}{l}0221 \text { Religion and theology } \\
0222 \text { History and archaeology } \\
0223 \text { Philosophy and ethics }\end{array}$ \\
\hline & 023 Languages & $\begin{array}{l}0231 \text { Language acquisition } \\
0232 \text { Literature and linguistics }\end{array}$ \\
\hline \multirow[t]{2}{*}{$\begin{array}{l}03 \text { Social sciences, } \\
\text { journalism and } \\
\text { information }\end{array}$} & 031 Social and behavioural sciences & $\begin{array}{l}0311 \text { Economics } \\
0312 \text { Political sciences and civics } \\
0313 \text { Psychology } \\
0314 \text { Sociology and cultural studies }\end{array}$ \\
\hline & 032 Journalism and information & $\begin{array}{l}0321 \text { Journalism and reporting } \\
0322 \text { Library, information and archival } \\
\text { studies }\end{array}$ \\
\hline \multirow[t]{2}{*}{$\begin{array}{l}04 \text { Business, } \\
\text { administration and law }\end{array}$} & 041 Business and administration & $\begin{array}{l}0411 \text { Accounting and taxation } \\
0412 \text { Finance, banking and insurance } \\
0413 \text { Management and administration } \\
0414 \text { Marketing and advertising } \\
0415 \text { Secretarial and office work } \\
0416 \text { Wholesale and retail sales } \\
0417 \text { Work skills }\end{array}$ \\
\hline & 042 Law & 0421 Law \\
\hline
\end{tabular}




\begin{tabular}{|c|c|c|}
\hline Broad field & Narrow field & Detailed field \\
\hline \multirow{4}{*}{$\begin{array}{l}05 \text { Natural sciences, } \\
\text { mathematics and } \\
\text { statistics }\end{array}$} & 051 Biological and related sciences & $\begin{array}{l}0511 \text { Biology } \\
0512 \text { Biochemistry }\end{array}$ \\
\hline & 052 Environment & $\begin{array}{l}0521 \text { Environmental sciences } \\
0522 \text { Natural environments and wildlife }\end{array}$ \\
\hline & 053 Physical sciences & $\begin{array}{l}\text { 0531 Chemistry } \\
0532 \text { Earth sciences } \\
0533 \text { Physics }\end{array}$ \\
\hline & 054 Mathematics and statistics & $\begin{array}{l}0541 \text { Mathematics } \\
0542 \text { Statistics }\end{array}$ \\
\hline $\begin{array}{l}06 \text { Information and } \\
\text { Communication } \\
\text { Technologies (ICTs) }\end{array}$ & $\begin{array}{l}061 \text { Information and Communication } \\
\text { Technologies (ICTs) }\end{array}$ & $\begin{array}{l}0611 \text { Computer use } \\
0612 \text { Database and network design and } \\
\text { administration } \\
0613 \text { Software and applications } \\
\text { development and analysis }\end{array}$ \\
\hline \multirow[t]{3}{*}{$\begin{array}{l}07 \text { Engineering, } \\
\text { manufacturing and } \\
\text { construction }\end{array}$} & $\begin{array}{l}071 \text { Engineering and engineering } \\
\text { trades }\end{array}$ & $\begin{array}{l}\text { 0711 Chemical engineering and } \\
\text { processes } \\
0712 \text { Environmental protection } \\
\text { technology } \\
0713 \text { Electricity and energy } \\
0714 \text { Electronics and automation } \\
0715 \text { Mechanics and metal trades } \\
0716 \text { Motor vehicles, ships and aircraft }\end{array}$ \\
\hline & 072 Manufacturing and processing & $\begin{array}{l}0721 \text { Food processing } \\
0722 \text { Materials (glass, paper, plastic } \\
\text { and wood) } \\
0723 \text { Textiles (clothes, footwear and } \\
\text { leather) } \\
0724 \text { Mining and extraction }\end{array}$ \\
\hline & 073 Architecture and construction & $\begin{array}{l}0731 \text { Architecture and town planning } \\
0732 \text { Building and civil engineering }\end{array}$ \\
\hline
\end{tabular}




\begin{tabular}{|c|c|c|}
\hline Broad field & Narrow field & Detailed field \\
\hline \multirow[t]{4}{*}{$\begin{array}{l}08 \text { Agriculture, forestry, } \\
\text { fisheries and veterinary }\end{array}$} & 081 Agriculture & $\begin{array}{l}0811 \text { Crop and livestock production } \\
0812 \text { Horticulture }\end{array}$ \\
\hline & 082 Forestry & 0821 Forestry \\
\hline & 083 Fisheries & 0831 Fisheries \\
\hline & 084 Veterinary & 0841 Veterinary \\
\hline \multirow[t]{2}{*}{09 Health and welfare } & 091 Health & $\begin{array}{l}0911 \text { Dental studies } \\
0912 \text { Medicine } \\
0913 \text { Nursing and midwifery } \\
0914 \text { Medical diagnostic and treatment } \\
\text { technology } \\
0915 \text { Therapy and rehabilitation } \\
0916 \text { Pharmacy } \\
0917 \text { Traditional and complementary } \\
\text { medicine and therapy }\end{array}$ \\
\hline & 092 Welfare & $\begin{array}{l}0921 \text { Care of the elderly and of } \\
\text { disabled adults } \\
0922 \text { Child care and youth services } \\
0923 \text { Social work and counselling }\end{array}$ \\
\hline \multirow[t]{4}{*}{10 Services } & 101 Personal services & $\begin{array}{l}1011 \text { Domestic services } \\
1012 \text { Hair and beauty services } \\
1013 \text { Hotel, restaurants and catering } \\
1014 \text { Sports } \\
1015 \text { Travel, tourism and leisure }\end{array}$ \\
\hline & $\begin{array}{l}102 \text { Hygiene and occupational health } \\
\text { services }\end{array}$ & $\begin{array}{l}1021 \text { Community sanitation } \\
1022 \text { Occupational health and safety }\end{array}$ \\
\hline & 103 Security services & $\begin{array}{l}1031 \text { Military and defence } \\
1032 \text { Protection of persons and } \\
\text { property }\end{array}$ \\
\hline & 104 Transport services & 1041 Transport services \\
\hline \multicolumn{3}{|c|}{$\begin{array}{l}\text { In addition to the detailed fields in the table above; "0", " } 8 \text { " and "9" may be used (see also the guidelines in Sections } 7 \text { and } \\
\text { 8): }\end{array}$} \\
\hline \multicolumn{3}{|c|}{$\begin{array}{l}\text { '8' is used at the narrow and detailed field level when classifying inter-disciplinary or broad programmes and qualifications } \\
\text { to the broad field in which the greater part of the intended learning time is spent (e.g. O288 'Inter-disciplinary programmes } \\
\text { and qualifications involving arts and humanities'). ' } 0 \text { ' is used when no further information is available about the field than } \\
\text { the field description at the next higher level of the classification hierarchy (i.e. at the broad field or at the narrow field level). }\end{array}$} \\
\hline \multicolumn{3}{|c|}{$\begin{array}{l}\text { ' } 9 \text { ' is used at the detailed field level when classifying programmes and qualifications which do not fit within any of the listed } \\
\text { detailed fields. }\end{array}$} \\
\hline
\end{tabular}


The International Standard Classification of Education (ISCED) is a member of the United Nations International Family of Economic and Social Classifications and is the reference classification for organizing education programmes and related qualifications by levels and fields of education. ISCED was first developed in the 1970s as the internationally-agreed framework for assembling, compiling and analysing cross-nationally comparable statistics on education.

The availability of a common international classification is only the first step towards the collection of comparable data. The second step is to ensure a consistent application of the classification across countries. The 2011 ISCED revision concentrates primarily on changes to the levels of education of programmes (ISCED-P) and introduces, for the first time, a classification of levels of educational attainment based on qualifications (ISCED-A). Adopted in 2013, ISCED-F describes and categorises the revised fields of education and training at the secondary, post-secondary and tertiary levels of education as defined in ISCED 2011.

The UNESCO Institute for Statistics (UIS) is the custodian of the ISCED family of classifications (ISCED-P, ISCED-A and ISCED-F). The UIS is responsible for their development, maintenance, updating and revision. The Institute provides guidance on the effective and consistent use of ISCED for international data collection and analysis.

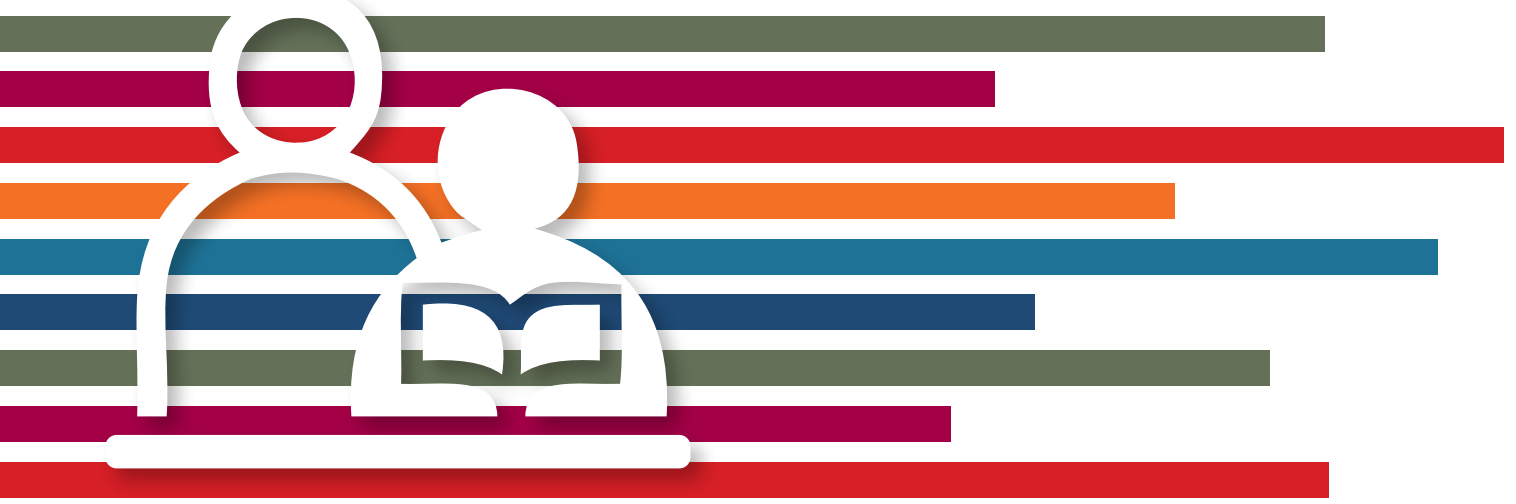

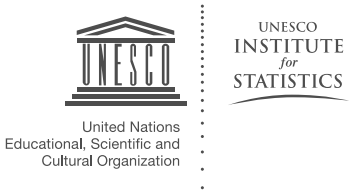

The UNESCO Institute for Statistics (UIS) is the statistical office of the United Nations Educational, Scientific and Cultural Organization (UNESCO) and is the UN depository for internationally comparable statistics in the fields of education, science and technology, culture and communication. 